\title{
Wearable technology and intermittent health care monitoring: The wave is here, the tsunami is coming
}

\author{
James R. Edgerton, MD, FACS, FACC, FHRS
}

From the Baylor Scott \& White Research Institute, The Heart Hospital Baylor Plano, Plano, Tex.

Disclosures: J.R.E. is on the speakers' bureau for AtriCure.

Received for publication July 20, 2018; accepted for publication July 21, 2018; available ahead of print Aug 31 , 2018

Address for reprints: James R. Edgerton, MD, FACS, FACC, FHRS, PO Box 190667, Dallas, TX, 75219 (E-mail: JamesEdgertonMD@gmail.com).

J Thorac Cardiovasc Surg 2019;157:244-5

$0022-5223 / \$ 36.00$

Copyright (c) 2018 by The American Association for Thoracic Surgery

https://doi.org/10.1016/j.jtcvs.2018.07.060

In this issue of the Journal, Gillinov and colleagues ${ }^{1}$ present an analysis of data collected during their 2015 index study. ${ }^{2}$ That study ${ }^{2}$ importantly demonstrated that performing an ablation procedure concomitantly with a mitral valve procedure significantly reduced the incidence of atrial fibrillation, atrial flutter, or atrial tachycardia (AF/AFL/AT) detected by 72 hour-Holter monitoring at 6 and 12 months. A subanalysis showed no difference in efficacy between pulmonary vein isolation and the biatrial maze procedure, but the authors acknowledged that the study lacked sufficient power to make that distinction. Nested in the index study was a project to develop badly needed methodology to properly analyze the contribution of serial binary (AF/ AFL/AT or no AF/AFL/AT) data such as weekly transtelephonic monitoring. In this article, Gillinov and colleagues ${ }^{1}$ present the analytic methodology so developed and demonstrate it by using it to analyze the weekly 90 -second rhythm strips recorded during the index study. The prevalence (proportion of patients in AF/AFL/AT at any given time point) but not the load (proportion of transtelephonic monitoring strips recording AF/AFL/AT) was reduced. From this finding, they conclude that a biatrial maze procedure may be more effective than pulmonary vein isolation in reducing AF/AFL/AT during the 12 months after surgery. As Gillinov and colleagues ${ }^{1}$ have stated, this article attempts to strike a balance between a new methodology study and one that by some analyses indicates that a biatrial maze procedure is superior to pulmonary vein isolation alone. It is important to note that these data and conclusion are complementary and not contradictory to those presented in the index study. ${ }^{2}$

This study comes at a time when the American Heart Association has called for atrial fibrillation to be reported not in a binary fashion (present or absent beyond a minimum arbitrary amount of time such as 30 seconds) but as the burden of AF (percentage of time spent in AF/AFL/AT). ${ }^{3}$ It also comes when we are in an explosion of wearable technology and remote patient monitoring. Best Buy (Best Buy Co., Inc, Richfield, Minn) is now entering the health care market and sees remote patient monitoring as a strategic

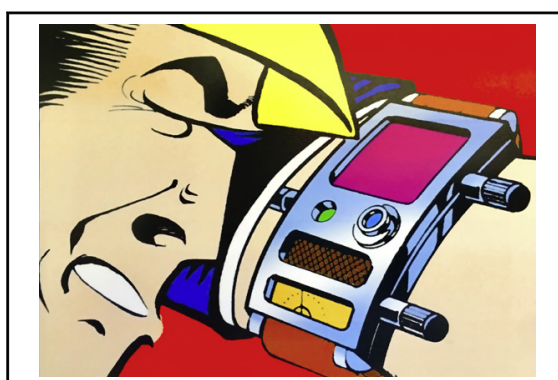

Wearable technology has evolved from futuristic to the future of patient monitoring.

\section{Central Message}

As use of wearable health care monitoring rapidly expands, the applications will reside in multifunctional devices and be intermittently obtained. Methodology is needed to interpret the data properly.

See Article page 234

growth area. ${ }^{4}$ AliveCor (AliveCor, Inc, Mountain View, Calif) uses deep machine learning to detect $\mathrm{AF}^{5}$ in its consumer device and can now be paired with an Apple Watch (Apple, Cupertino, Calif) in wearable form. This modality has already been validated ${ }^{6}$ for clinical use, and its use in research trials is sure to expand because of the expense of intermittent continuous monitoring. Wearable monitoring technology is also finding applications in other disciplines, such as diabetes, heart failure, and even intravascular stents that can detect the development of in-stent restenosis. Many of these applications will reside in multifunctional devices (such as smart phones), and thus the data acquisition will be intermittent or on demand.

Knowing how to analyze and apply the data acquired will be critically important. So perhaps the most important part of this excellent report is the elucidation of how to analyze and interpret intermittent monitoring. Gillinov and colleagues ${ }^{1}$ are to be congratulated on this innovative and forward-thinking work. Confirmatory trails and further work are needed in the areas of burden, load, and prevalence.

\section{References}

1. Blackstone EH, Chang HL, Rajeswaran J, Parides MK, Ishwaran H, Li L, et al Biatrial maze procedure versus pulmonary vein isolation for atrial fibrillation during mitral valve surgery: new analytical approaches and end points. $J$ Thorac Cardiovasc Surg. 2019;157:234-43.e9.

2. Gillinov AM, Gelijns AC, Parides MK, DeRose JJ Jr, Moskowitz AJ, Voisine P, et al; CTSN Investigators. Surgical ablation of atrial fibrillation during mitralvalve surgery. N Engl J Med. 2015;372:1399-409. 
3. Chen LY, Chung MK, Allen LA, Ezekowitz M, Furie KL, McCabe P, et al. Atrial fibrillation burden: moving beyond atrial fibrillation as a binary entity: a scientific statement from the American Heart Association. Circulation. 2018; 137:e623-44.

4. Sturman S. Best Buy is set to enter the healthcare space. Available at: https://www. healthcareglobal.com/public-health/best-buy-set-enter-healthcare-space. Accessed August 21, 2018
5. Alivecor. Bridging the gap between wearables and healthcare. Available at: https:// www.alivecor.com/technology/. Accessed August 21, 2018

6. Bumgarner JM, Lambert CT, Hussein AA, Cantillon DJ, Baranowski B, Wolski K, et al. Smartwatch algorithm for automated detection of atrial fibrillation. J Am Coll Cardiol. 2018;71:2381-8.

7. Chen X, Assadsangabi B, Hsiang Y, Takahata K. Enabling angioplasty-ready "smart" stents to detect in-stent restenosis and occlusion. Adv Sci. 2018;5:1700560. 